\title{
O DESAFIO DE COMPREENDER A NATUREZA NA OBRA DE MILTON SANTOS
}

\author{
Marília Luiza Peluso
}

p. $22-31$

Como citar este artigo:

PELUSO, M. L. O DESAFIO DE COMPREENDER A NATUREZA NA OBRA DE MILTON SANTOS. Revista Eletrônica: Tempo - Técnica Território, v.4, n.1 (2013), p. 22:31 ISSN: 2177-4366.

DOI: https://doi.org/10.26512/ciga.v4i1.16317

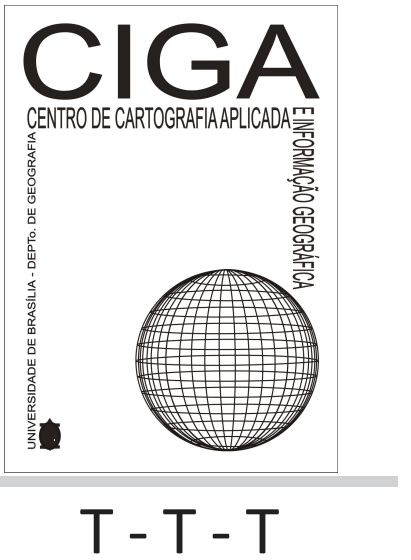

Revista Eletrônica: Tempo - Técnica - Território, V.4, N.1 (2013), 22:31 ISSN : 2177-4366

DOI: https:// doi.org/10.26512/ ciga.v4i1.16317

isponível em:

http://inseer.ibict.br/ciga/index.php/ciga/article/viewFile/168/127

Este obra está licenciado com uma Licença Crea tive Commons Atribuição-NãoComercial 4.0 Inter nacional. 


\title{
O DESAFIO DE COMPREENDER A NATUREZA NA OBRA DE MILTON SANTOS
}

\author{
Marília Luiza Peluso \\ Bacharel e Licenciada em Geografia \\ Mestre em Planejamento Urbano e Regional \\ Doutora em Psicologia Social \\ Professora Pesquisadora Colaboradora \\ Departamento de Geografia \\ UnB - Brasília/DF \\ E-mail:peluso@unb.br
}

\begin{abstract}
Resumo: Pretende-se, neste artigo, discutir a maneira como Milton Santos teoriza o conceito de Natureza e como ela se integra à totalidade espacial. Duas perguntas norteiam o texto: “Qual o lugar da Natureza no jogo histórico das superestruturas e da infraestrutura, na formação econômica e social?" e "Pode-se conhecer integral e racionalmente a Natureza no atual período técnicocientífico-informacional”? A premissa é de que a Natureza é uma constante preocupação de Santos, mas seu sentido na totalidade não é imediatamente visível, e deve por isso ser escavado em seus trabalhos. A ideia do artigo é contribuir para a reflexão sobre os caminhos de Milton Santos, sem chegar a resultados definitivos, mas contribuir para novas reflexões.
\end{abstract}

Palavras-chave: Milton Santos; Natureza; totalidade espacial; período técnico-científicoinformacional.

\begin{abstract}
It is intended, in this article, to discuss how Milton Santos theorizes the concept of Nature and how it is integrated to the spatial totality. Two questions guide the text: "What is the place of nature in historic game of superstructure and infrastructure, in the economic and social formation?" And "Is it possible to know the nature fully and rationally in the current technicalscientific-informational period?” The premise is that Nature is a constant concern to Santos, but its meaning in the totality is not immediately visible, and should therefore be deepened in his work. The idea of this article is to contribute to the reflection about the ways of Milton Santos, without reaching definite results, but contribute to new thinkings.
\end{abstract}

Keywords: Milton Santos; Nature; spatial totality; technical-scientific-informational period.

Resumen: La intención de este artículo es discutir cómo Milton Santos teoriza el concepto de Naturaleza y cómo ella se integra a la totalidad espacial. Dos preguntas guían el texto: a) ?cuál es el lugar de la Naturaleza en el histórico juego de superestructura y infraestructura en la formación económica y social? y b) puede conocerse plenamente y racionalmente la Naturaleza en el período técnico-científico-informacional de la actualidad? Nuestra premisa es que la Naturaleza es una preocupación constante para Santos, pero su significado en la totalidad no es inmediatamente visible, y por lo tanto se debe adentrar en su obra para captar su significación. La idea de este trabajo no es llegar a resultados definitivos sino contribuir a la reflexión y a nuevas formas de pensar sobre los caminos teóricos de Milton Santos.

Palabras clave : Milton Santos; Naturaleza; totalidad espacial; período técnico-científicoinformacional.

Revista Eletrônica: Tempo - Técnica - Território, V.4, N.1 (2013), 22: 31 ISSN: 2177-4366 


\section{Introdução}

A obra de Milton Santos constitui para todos que trabalham os problemas da atualidade, sejam geógrafos ou não, uma fonte sempre renovada de reflexões e estímulos. É um desafio e, ao mesmo tempo um prazer, falar dos conceitos que ele desenvolveu ao longo de seu trabalho intelectual. O espaço foi a grande preocupação de Santos, teorizado por via da sociedade e da natureza em vários momentos e de diversas maneiras, com novas abordagens para as questõeschaves da Geografia.

Pretende-se, como escolha dentre as múltiplas teorizações de Santos, apresentar neste artigo uma pequena discussão sobre a maneira como ele aborda o conceito de Natureza e como ela se integra ao espaço. E por que "Natureza”? Porque é conceito chave em Geografia, que consta desde os primeiros geógrafos que buscaram sistematizar a área de estudos da disciplina. A Geografia pesquisa a maneira como a sociedade produz o espaço a partir das relações entre os homens e destes com a natureza nos vários momentos da história da cultura e das civilizações. Tal viés científico não é aleatório, mas resulta da divisão social do trabalho científico, segundo o qual à ciência geográfica coube trabalhar com a área de contato entre natureza e sociedade, uma tarefa muito rica, mas que origina discussões e polêmicas até os dias hoje.

A escolha do tema já se mostrou uma tarefa difícil, apesar de gratificante, pela complexidade do pensamento de Santos, pelas inúmeras vozes que se cruzam em seus escritos e pelo volume de suas publicações. Portanto, nova escolha deve ser feita e se trata da bibliografia a ser consultada, essencial para delimitar o tema. Parte-se das indagações suscitadas pela leitura, e várias releituras, do capítulo 1, do livro “Sociedade e Espaço” intitulada “Sociedade e espaço: a formação social como teoria e como método”. Outras indagações provem do Prólogo do livro “Espaço e Método”, intitulado “Uma palavrinha a mais sobre a natureza e o conceito de espaço”.

No primeiro trabalho, Santos propõe a incorporação do espaço nas estruturas da formação econômica e social (FES), denominando-a de “formação econômica, social e espacial”, pois “o espaço reproduz a totalidade social na medida em que essas transformações são determinadas por necessidades sociais, econômicas e políticas” (SANTOS, 1979, p. 18). No segundo trabalho, Santos, logo no início, escreve: “A essência do espaço é social. Nesse caso, o espaço não pode ser apenas formado pelas coisas, os objetos geográficos, naturais e artificiais, cujo conjunto nos dá a Natureza.” (SANTOS, 1985, p. 1). O que significaria a afirmação? De que a Natureza não faz parte 
do social? A questão é pertinente, ainda mais quando Santos distingue, parágrafos antes, “ingredientes sociais e a 'natureza'“ (SANTOS, 1985, p. 1).

Duas perguntas podem ser feitas. A primeira é “Qual o lugar da Natureza no jogo histórico das superestruturas e da infraestrutura, na formação econômica e social?” A segunda pergunta pode ser assim formulada: "Pode-se conhecer integral e racionalmente a Natureza no atual período técnico-científico-informacional”? Parte-se da premissa de que a Natureza é uma constante nos trabalhos de Santos, mas seu sentido na totalidade não é imediatamente visível, e deve por isso ser escavado em seus textos. As respostas a serem escavadas não pretendem chegar a resultados definitivos sobre a totalidade natureza/sociedade, mas levantar novas questões e novas perguntas a serem pesquisadas, além de contribuir para a reflexão sobre a Natureza no caminho de Milton Santos.

Há muito de subjetividade no que se vai desenvolver, ao contrário do que recomendava o mestre Santos, quando escreveu em “O Estado-nação como espaço, totalidade e método” (SANTOS, 2002, p. 44): “entretanto, num nível muito próximo ao pesquisador, aumentam as possibilidades de erro na escolha das variáveis, pelo risco de subjetivação”. Entretanto, o que se pode fazer? Apesar da busca pela objetividade, sempre caímos na armadilha da escolha das variáveis. Assim, para tornar o texto o mais objetivo possível, seguem-se dois caminhos: no primeiro, será abordada a historicidade da natureza e no segundo, o conhecimento da natureza como expressão da razão. Talvez no segundo caminho esteja subjacente a questão da verdade, mas não se pode afirmar com certeza que a questão tenha uma resposta clara. Afinal, sempre é necessário deixar espaço para mais questionamentos.

\section{A historicidade da Natureza na obra de Milton Santos}

Em artigo de 1982, na coletânea “Novos rumos da Geografia brasileira”, Santos escreve sobre a contribuição do marxismo para os novos tempos geográficos e enfatiza

Esse instrumental crítico somente pode provir de um conhecimento abalizado das categorias e de um domínio igualmente assentado na história, sobretudo dos seus dados presentes. Fora daí, o risco é grande de chegar a conclusões que afastam do real em vez de permitir sua interpretação” (SANTOS, 1982a, p. 133).

Nessa frase, creio eu, encontram-se duas vertentes importantes que me interessam: o conhecimento assentado na história e o conhecimento como interpretação do real. Se considerarmos que o conhecimento é assentado na história, o conhecimento da Natureza também é assentado na 
história; se o conhecimento é a interpretação do real, a Natureza deve ser entendida dentro do realtotal do presente.

Para tanto os conceitos não devem ser congelados e "é indispensável levar em conta as novas condições históricas, tanto as infraestruturais quanto supra-estruturais [...]”(SANTOS, 1982, p. 134). Assim, faço a seguinte pergunta: é a própria Natureza que muda, ou é seu conceito que se altera? Posso responder com razoável grau de certeza: para Milton Santos o que é a Natureza depende de sua posição como elemento da totalidade espacial dinâmica e de sua relação com os outros elementos. Baseio-me nas palavras do próprio Milton, quando escreve:

O que nos interessa é o fato de que a cada momento histórico cada elemento muda seu papel e a sua posição no sistema temporal e no sistema espacial e, a cada momento, o valor de cada qual deve ser tomado da sua relação com os demais elementos do todo (SANTOS, 1985, p. 9).

Falar na historicidade da Natureza não é lembrar, sempre e novamente, de que nos encontramos diante de uma segunda Natureza configurada pela sociedade. Creio que a análise pode abordar também outro ângulo e apesar do pouco tempo para desenvolvê-lo, vale a pena tentar.

Deve-se considerar a interação e a interdependência entre os elementos componentes do espaço como faz Santos em 1985. Nesse momento, ele trabalha a Natureza como “meio ecológico”, "o conjunto de complexos territoriais que constituem a base física do trabalho humano" (SANTOS, 1985, p. 6). Os elementos do espaço são vistos pela ótica do trabalho e da produção, para os quais a Natureza é um suporte no período técnico-científico.

Se a Natureza só pode ser compreendida dentro do real-total do presente - “A história é o hoje de cada atualidade” (SANTOS, 1994, p. 90) - não significa que ela também não tenha uma história, mas dentro da espaço-temporalidade dos homens. É o que Santos (1994, p. 15) chama de "Sistemas de Natureza sucessivos”, que se sucedem desde quando o homem retirava de seu ambiente tudo aquilo de que necessitava até sua transformação plena em Natureza Social (SANTOS, 1994, p. 16) no período técnico-científico-informacional. Temos, então, nesses sistemas, a passagem da Natureza natural, mesmo já segunda natureza, à natureza-objeto artificial:

Nesse nosso mundo se estabelece, por isso mesmo, um novo sistema da natureza, uma natureza que, graças exatamente ao movimento ecológico, conhece o ápice de sua desnaturalização (SANTOS, 1994, p. 90). 
Desnaturalização porque, tomada pela mídia, o discurso do meio ambiente exagera aspectos da natureza que lhe interessam e perde-se a noção de conjunto, de totalidade história, de sistema de coisas, de dado permanente para a vida e o trabalho dos homens. A Natureza histórica é transformada em natureza espetáculo (SANTOS, 1992).

Em 1997, Santos retoma a historicidade da natureza, mostrando o antes e o agora, e agora, uma natureza transformada em objeto, quando então reforça ideias que desenvolvera anteriormente:

\begin{abstract}
No princípio, tudo eram coisas, enquanto hoje tudo tende a ser objeto, já que as próprias coisas, dádivas da natureza, quando utilizadas pelos homens, a partir de um conjunto de intenções sociais, passam, também a ser objetos. Assim, a natureza se transforma em um verdadeiro sistema de objetos e não mais de coisas e, ironicamente, é o próprio movimento ecológico que completa o processo de desnaturalização da natureza, dando a esta última um valor (SANTOS, 1997, p. 53)
\end{abstract}

Nesta passagem das reflexões de Santos fica clara a passagem da concepção mágica da Natureza, em que se projetavam nela as características humanas (DUARTE, 1986) até a natureza apropriada para o trabalho nas manufaturas, em que é um recurso para a produção de mercadorias. Ou seja, a natureza foi transformada em recurso, como Milton escreveu em vários momentos, e como tal, divisível, transformável e monetarizada. Ela mudou sua posição no sistema espaçotemporal e sua relação agora não é mais de proporcionar dádivas para satisfazer necessidades humanas, mas tomada pelas técnicas e pela divisão social do trabalho, é um recurso do processo de produção e um momento dos tempos dos modos de produção (SANTOS, 1997).

O conceito de natureza se alterou; ela deixou de ser sujeito - a Natureza dos tempos primordiais que jamais conheceremos, e adquiriu a condição de objeto - a natureza do período urbano atual, em que a cidade é o lugar mais perfeito do predomínio das técnicas. Ou seja, deixou de ser a Primeira Natureza e se transformou, para sempre, em segunda natureza. Santos (1997, p. 203) escreve que a antiga distinção entre primeira natureza e a segunda natureza deve ser flexibilizada, pois “a natureza já modificada pelo homem também é primeira natureza”, visto que “a produção não é mais ação do trabalho sobre a natureza, mas trabalho sobre o trabalho”.

Pode-se dizer, então, que se o papel da natureza muda no processo de produção, a Natureza como elemento na totalidade do sistema também já não é mais o mesmo. Não quero, porém, concluir taxativamente e deixarei essa resposta em aberto para que se façam reflexões sobre a coisa em si - a natureza - ou seu valor - a natureza para o modo de produção. No jogo histórico das superestruturas e da infra-estrutura tem-se agora um recurso para o trabalho.

\title{
2. O conhecimento da natureza como expressão da razão
}

Revista Eletrônica: Tempo - Técnica - Território, V.4, N.1 (2013), 22: 31 ISSN: 2177-4366 
Na segunda parte, pretende-se discutir a maneira como Santos trata da razão em seus trabalhos, analisando o que escreve sobre a natureza. Vou fazê-lo utilizando apenas duas obras, “Pensando o espaço do homem”, livro de 1982, e “A Natureza do espaço. Técnica e tempo; razão e emoção”, de 1997. Aqui, as categorias-chave para a discussão são ideologia e símbolo, Parece-me que nesses dois livros, ideologia e símbolo, apesar de parecerem semelhantes, inscrevem-se num contexto espaço-temporal que as tornam bastante diferentes.

No primeiro livro, em 1982, ideologia e símbolo fetichizam o homem e a realidade, mas parece que ainda se pode chegar a uma verdade se for possível desvendá-los, à ideologia e ao símbolo, mostrar sua falsidade e superá-los. No segundo, ideologia e símbolo se incorporaram de tal maneira à realidade, que se tornaram a própria verdade e o fetiche se transforma na realidade.

Vamos ver em algumas poucas citações como a passagem ocorre. Em 1982, Milton Santos aborda a ideologia e o símbolo como encobridores da realidade, como aparência, que dificultam, ou mesmo impedem, conhecer a verdade. “O objeto”, para ele, “possui duas faces: a verdadeira, que não se entrega facilmente ao observador, e a face visível, moldada pela ideologia” (SANTOS, 1982b, p. 23). Conhecer, então, é encontrar a essência sob as aparências, é encontrar a face oculta do objeto.

Em seguida, quando discute a arquitetura funcional da Bauhaus e sua modernidade ideológica de uma ordem voltada às exigências da produção, que transforma tudo em valor de troca, em objetos manufaturados que recusam a natureza como modelo, chama-a de "arquitetura como mass-media, prenhe de intencionalidades e de simbolismo” (SANTOS, 1982b, p. 24). Portanto, "Desfetichizar o homem e o espaço é arrancar à Natureza os símbolos que ocultam a sua verdade” (SANTOS, 1982b, p. 25). Ao final da frase, Santos remete em nota de fim de capítulo a Ernst Cassirer.

É interessante observar o diálogo que Santos estabelece com Cassirer. Diria que é diálogo de oposição, em que usa um autor para escrever o oposto dele, pois Cassirer considera o símbolo a verdadeira distinção do homem, a mudança qualitativa essencial que o tornou humano, quando escreve

o homem descobriu, por assim dizer, um novo método para adaptar-se ao seu ambiente. Entre o sistema receptor e o efetuador, que encontramos em todos os animais, observamos no homem um terceiro elo, que podemos descrever como sistema simbólico (CASSIRER, 1994, p. 47/48). 
A dimensão simbólica o faz viver numa nova dimensão da realidade, visto que "o homem vive em um ambiente simbólico” (CASSIRER, 1994, 48). Para Santos, porém, e aqui estou fazendo uma interpretação, reconheço, o que distingue o homem é o pensamento racional, que lhe permite conhecer a realidade para além do símbolo e para além da ideologia e, também, pode-se acrescentar, para além do fetiche da mercadoria.

A natureza, livre da ideologia, do símbolo e do fetiche, seria conhecida em sua condição de elemento da totalidade, livre do subjetivo; conhecida pela razão no real-concreto de um mundo sem ideologia e sem simbolismo. Vejo aqui aquele ideal da razão, em que o conhecimento seria capaz de trazer o mundo, a natureza, a sociedade perante si e desvendá-los integralmente (FIGUEIREDO, 1993).

No segundo livro, de 1997, Milton Santos não desistiu de buscar a verdade e conhecer o real-concreto em toda sua plenitude, mas agora, a ideologia e o símbolo passam a fazer parte da realidade, não mais a escondê-la. Ou talvez exatamente para escondê-la? Santos não desacredita da razão, mas ela não é mais a razão iluminista e filosófica que permite compreender o mundo e a natureza, mas uma razão domada que produz "uma racionalidade conforme aos fins e os meios, obedientes à razão do instrumento, à razão formalizada, ação deliberada por outros, informada por outros” (SANTOS, 1993, p. 91). A razão perde a autonomia de conhecer.

Se, em 1982, a ideologia e o símbolo estavam fora da realidade e procuravam fetichizá-la, em 1997,

A ideologia produz símbolos, criados para fazer parte da vida real e que freqüentemente tomam a forma de objetos. A ideologia é, ao mesmo tempo, um dado da essência e um dado da existência, neste fim de século XX (SANTOS, 1997, p. 102).

Qual a razão em 1997? É a razão hegemônica das técnicas, a razão universal imposta pela ordem global, que impõe a racionalidade operacional da organização (SANTOS, 1997, p. 272). A razão técnica que transforma a natureza sempre em segunda natureza, continuamente subjugada pelo modo de produzir que a todos e a tudo domina, homens e natureza. Mas, dialeticamente, a mesma razão instrumental produz uma contra-razão: “objetivamente, pode-se dizer também que, a partir dessa racionalidade hegemônica, instalam-se paralelamente contra-racionalidades” (SANTOS, 1997, p. 246).

Dialeticamente, também, a razão deslocou-se do centro para a periferia, para a contraracionalidade dos pobres, dos migrantes, dos excluídos, das minorias, 
de um ponto de vista econômico, entre as atividades marginais, tradicional ou recentemente marginalizadas; e, de um ponto de vista geográfico, nas áreas menos modernas e mais 'opacas', tornadas irracionais pelos usos econômicos (SANTOS, 1997, p. 246).

A razão deslocou-se para outras formas de racionalidade, "racionalidades paralelas, divergentes e convergentes ao mesmo tempo” (SANTOS, 1997, p. 246). E, então, para terminar, pergunto se ainda se pode conhecer a natureza como elemento do real-concreto em toda sua realidade e concretude, ou se só poderemos conhecê-la como ideologia e símbolo, como recurso e meio ecológico em que ela se transformou no atual mundo globalizado, técnico-científicoinformacional.

\section{Para concluir, novas perguntas}

E a Verdade, quem irá conhecê-la? E a Natureza? A nova racionalidade vai permitir a interpretação real da Natureza ou afastar-nos dela? São perguntas que permanecem para novas reflexões.

\section{REFERÊNCIAS BIBLIGRÁFICAS}

CASSIRER, E. Ensaio sobre o homem. Martins Fontes: São Paulo, 1994.

DUARTE, R. A. de P.. Marx e a natureza em o Capital. São Paulo: Loyola, 1986.

FIGUEIREDO. L. C.. Os lugares da psicologia. In SEMANA DA PSICOLOGIA DA UNESP, Assis, set 1993.

SANTOS, M.. A natureza do espaço. Técnica e tempo. Razão e emoção. Hucitec: São Paulo, 1997.

Da totalidade ao lugar. São Paulo: Editora da Universidade de São Paulo, 2005, p. 43-55. . Técnica, espaço, tempo. Globalização e meio técnico-científico-informacional. Hucitec: São Paulo, 1994.

.A redescoberta da Natureza. In Estudos Avançados, 6(14), 1992, p. 1-15. Disponível em: http://www.scielo.br/pdf/ea/v6n14/v6n14a07.pdf - consultado em 21/09/2010

.Espaço e método. São Paulo: Nobel, 1985. 
. Alguns problemas atuais da contribuição marxista à Geografia. In SANTOS, M.(org.). Novos rumos da Geografia brasileira. São Paulo: Hucitec, 1982 a, p. 131-143.

. Pensando o espaço do homem. Hucitec: São Paulo, 1982 b. 